\title{
Effective Ways to Improve the Service Quality of University Library
}

\author{
Yang Xing \\ Jilin Agricultural University, Changchun 130118, China \\ 37566208@qq.com
}

\begin{abstract}
University library is an important place for providing information services for teachers and students. In order to make the role of the library better played, it needs to be strict in the requirements on the quality of library services and try to make improvement. To ensure that the maximum efficiency of the spread of knowledge and the library's resources are effectively used. Therefore, the service of a university library should be able to be evaluated. First of all, this paper begins with the problems of the service quality of university library, and then points out the significance of improving the quality of service by the advanced service quality evaluation system of university libraries at home and abroad. Then the effective ways to improve the service quality of university library are obtained. In this paper, through the analysis of the way to improve, tells the readers that it is very necessary development process and improving the quality of service is an imperative process.
\end{abstract}

Keywords: University library; Service quality; Promotion; Ways.

\section{Problems of Library Service Quality}

Service firstly requires to meet the needs of users, to help them solve problems and provide guidance for them.

The library service is the process and result of the guidance of the library to meet the needs of the information needs of college students. The result of service quality is the satisfaction of teachers and students. Due to the huge library resources, whether it is the library resources or the database resources, the user's demand is diversified. And the library carries this diversified demand. Due to the diverse needs of teachers and students, the library services have to be diversified and able to adapt to the trend of the times. But college library, facing the demand diversity and variability, is impossible to keep a permanent stability of service [1]. It always cannot proceed indifference, standardization of the assembly line work like line table, so as to ensure the reliability of product quality and consistency. Library services are operated by people, so the information needs are completed by the transmission among people and people. In the course of its transmission, it is inevitable that the information may be omitted or transmitted. Any change will affect the quality of service of the library, so it cannot give the satisfying results to teachers and students [2]. The quality of service of university library in development will be affected by many factors. Although China's university library has a significant development and progress in the overall development process, there are still a lot of problems in the collection, the level of service personnel, lack of management and so on.

\subsection{Slow and Dilapidated Book Update}

The library is a huge stack room, with a lot of books. In consequence, the updates and flows are a huge and complex task, therefore resulting in that the books are often dilapidated, which cannot drive the interests of teachers and students to read. And some libraries have a long time that in the library's software facilities and hardware facilities it cannot be effectively updated. The library also has the time limit of validity like the newspaper. Although the timeliness is not so short, it also needs to be updated especially the science and technology books. Also there are some vacant shelves, without books put on. While some of the books on the shelf are updated, but the books lost the research value are still on the shelves of resources which not only waste the space resources, but also cause a distress to the reader.

\subsection{Poor Administrator's Service}

The administrator has not been trained for a long time, which leads to the low service quality of some administrators. Their poor service attitude cannot give the reader with careful guidance, 
resulting in the loss of the reader's information resources. Some administrators do not responsible for anything, instead, they just take the library as a warehouse needed to be guarded. Or they don't know how to act, and ultimately they choose to provide a simple and mechanical service.

Some administrators lack the training, so their service ability is low. Facing the problems appearing in the service process, they cannot effectively solve them or take the feasible solution, and during the post, their service is not targeted. The shift patterns caused that the previous round did not solve the problem and it continued to hold, which also let them hard to concentrate on training, study and exchange on the new problems. As a result, the problems found in the service cannot be effectively solved. Therefore, it is necessary to focus on effective solutions to these problems, strengthen supervision, solve problems and improve their service level and quality.

\subsection{Backward Management}

Many administrators are experienced, but their progress of knowledge cannot keep up with the development of society. They only take work as a comfortable environment, not the pursuit of progress with the times, leading to the backwardness of the library services and so on. Science and technology are changing. The university library should also change with the progress of society. In the new era, the development of electronic science and technology is very fast, the library should also enhance the standard in service, but also do related training and learning. The development of electronic technology, electronic information and communication technology makes the library storage of information change [3]. University library should reform by closely following the changes, always maintain the advancement, and make sure to what students and teachers contact with are cutting-edge information and up-to-date information acquisition.

University library is not only a great building, but to draw lessons from the progress of each other in the management. The libraries of colleges and universities are not a static storage room, and the administrator is not a mechanical assembly line workers. On the contrary, library should be a dynamic process of development, and the administrator should be a transfer and communicator of advanced information. Concentrated large library knowledge and backward and lack of management concept make the library just become a decoration. Alexandria library curator said: the university library is like the beacon on the sea, giving guidance to the Night Stalker. They know their position, play their role, and strongly expressed their dream. Although the university library has developed a relatively complete management system, it still lacks validity and the timeliness. In the management philosophy, it is still following the experience of the past, seldom form the characteristics of modernization.

\section{Related Service Quality Evaluation Theory System}

\subsection{The Kano Model}

The Kano model is proposed by Dr. No Kiaki from Tokyo University Science in Japan, which is based on the analysis of customer satisfaction. It is divided into user's subjective perception (very satisfied, very dissatisfied) and objective product performance (the fundamental problem, adequate), so as to obtain the service quality: attractive quality (meet the service, customer satisfaction, the shortcomings are also acceptable), one-dimensional quality (service satisfaction, customer satisfaction, not satisfied with the shortcomings), no differences in the quality characteristics (whether the service is satisfying, the user will have satisfied or not satisfied results), essential quality characteristics (when the characteristics are met, the users feel it should be; if not, they will be dissatisfied), reverse quality characteristics (when the service is met, users are not satisfied; on the contrary, when the service is not met, they are satisfied).

\subsection{User Satisfaction Index Model}

User satisfaction index is a multi-layer composite index system, which is needed in the comprehensive reflection of the customer satisfaction in different industries in different industry even the whole country. It is the result of the evaluation of user satisfaction through a specific causal relationship model. It is a new type of macroeconomic indicators and quality evaluation indicators, which are actively studied and used in many countries. It is an empirical model to measure the degree 
of satisfaction and loyalty of users to products or services. Though the measurement of the satisfaction of the customer to the product and the service, obtain the product and the service quality evaluation value, so as to reflect the quality of the product and the service condition.

\subsection{Related Evaluation System}

Kano evaluation index system construction of index the user perceived service quality is divided into five attributes. Tangibility refers to library service personnel appearance and field service facilities and equipment and other tangible evidence. Reliability means library provides users with a safe and reliable service. Responsiveness means that the library's service personnel are willing to provide users with timely and effective service. Guarantee refers to the service personnel's professional knowledge and professional skills let the users to generate a sense of security and trust. Empathy refers to the service personnel of the library to provide the humanized service from the user's needs. That is, these five attributes directly affect the user's view of the quality of library service. These five attributes are decomposed into a specific evaluation index, as shown in table 1, which constitutes the evaluation index system of the user's expectations and feelings.

Table 1 Specific Evaluation Index

\begin{tabular}{|c|c|c|c|}
\hline Evaluation elements & Composition elements & $\begin{array}{c}\text { Expectation } \\
\text { (E) }\end{array}$ & $\begin{array}{c}\text { Perception } \\
\text { (P) }\end{array}$ \\
\hline \multirow{4}{*}{ Tangibility } & New service equipment & & \\
\hline & Charm of equipment & & \\
\hline & Staffs clothing is tidy and clear or not & & \\
\hline & Service and facilities are matched or not & & \\
\hline \multirow{5}{*}{ Reliability } & Fulfill the promise to the clients or not & & \\
\hline & Provides help or not & & \\
\hline & Fulfill the promise on time or not & & \\
\hline & The institution is reliable or not & & \\
\hline & Accurately record the service or not & & \\
\hline \multirow{4}{*}{ Responsiveness } & Time of not expecting to get feedback & & \\
\hline & Not expect to get timely service & & \\
\hline & Staffs are not enthusiastic in helping the clients & & \\
\hline & Staffs are too busy to provide timely service & & \\
\hline \multirow{4}{*}{ Guarantee } & Staffs are reliable & & \\
\hline & Relieved at the trading & & \\
\hline & Staffs are polite & & \\
\hline & Staffs can get help form the company & & \\
\hline \multirow{5}{*}{ Empathy } & Company do not provide single service & & \\
\hline & Staffs treat the clients equally & & \\
\hline & Not expect staffs to know about clients needs & & \\
\hline & Company do not consider for the benefit of the clients & & \\
\hline & Company cannot provide the service meet all the clients needs & & \\
\hline
\end{tabular}




\section{Significance of Improving Service Quality}

University Library has a huge collection of books, a wide range of categories, strong professional, and rich in data resources. It is one of the main sources for students to obtain knowledge, and it is also the place where the information to be taught is referred to. It plays a very important role in the cultivation and development of talents. With the development of economy, the amount of information of the expansion, and the social progress, the pursuit of the teachers and students on information resources is not only professional textbooks, but more and more diversified and individualized [4]. Library as the main way for college students to obtain information resources, library service quality becomes particularly important. it supports teachers and students research information acquisition, preparation of teaching resources, and improvement of reading. The library should play their own advantages in the era of the knowledge economy, so the development of library service quality is an opportunity, but also a challenge [5].

Especially under the information technology environment, students have changed passive learning to initiative seeking. They begin to actively looking for the development of information, which is more difficult for the library, more difficult to meet the needs of diverse students. And the students and teachers themselves have very high level of knowledge, and the level is also beyond the general reader, so the demand for professional and diverse needs of the demand is higher [6]. Therefore, under the circumstances of great environmental change, as well as personalized, diversified and specialized requirements of teachers and students, the construction and development of university library is more important. Therefore, university library must change the former passive service to active way to meet, improve service level and service quality, ensure the cultural heritage and improve the personnel quality.

In the new century, science and technology develops rapidly, our country pays more and more attention to scientific research, therefore the teaching of colleges and universities actively carry out a variety of scientific research activities, which needs higher requirements on library service. University library needs to follow the pace of the times to further enhance service level, improve the quality of service, develop from multi angle and full range, maximize play the role of library function, and let the library resources shine, so as to better provide effective service for the scientific development of colleges and universities.

\section{Ways to Improve the Service Quality of University Library}

\subsection{Improve the Quality of Service Personnel}

The first thing for college students entering into a university to do is to visit the library, listen to the library administrators to explain the library's history, the size of the collection, classification standards, searching and borrowing methods and so on. A library service quality is the place of measuring a school image and development of the school level. Therefore, it is necessary to strengthen training of staffs, improve their level of service, and improve their overall quality. Library staff is the premise for the library to carry out the work. In consequence, it is required to develop responsible and efficient staffs [7]. Strengthen their own moral cultivation, master the comprehensive ability to serve the readers, and serve the teachers and students. Strive to improve their ability to keep pace with the times and grasp the needs of readers and feedback. Take the initiative to serve the teachers and students and play the role of the transfer of information.

\subsection{Update Library Equipment}

University library is a place for teachers and students to look for information and cultivate wisdom. It has a lot of paper resources and data resources. In order to make better use of these resources, the facilities of the library must keep up with the changes and development of the times. Library should follow the progress of the times to introduce advanced electronic equipment, improve the hardware service facilities, and update the computer, electronic screen, printer and other hardware facilities. It also includes the library management system construction, the server and the network structure model, the network exchange function, the electronic reading room construction, the information network 
environment and so on. Library service methods often include telephone, Internet, fax, scanning, recording and so on. Some also use the wireless services, such as mobile phone library, and all of this need to rely on modern technology and equipment.

\subsection{Perfect Information Resources Sharing Service}

With the development of computer and science and technology progress, actively build a digital library, namely update of network technology, computer equipment, etc. For example, CNKI contains five or six thousand academic journals, and superstar electronic library has 25000 digital electronic books [8]. If these electronic information resources are all replaced by paper resources, though knowledge is infinite, the collection is limited. And a huge paper resources result in the time-consuming and energy-consuming to find information, but also the efficiency is limited. It is difficult to retrieve mass of paper resources, while the electronic virtual library collection in this aspect is extremely convenient and quick, which makes more readers enjoy more convenient and efficient service.

\subsection{Establish Brand Awareness}

Provide professional services for teachers and students. According to the books of different subjects, provide with relevant professional librarians who not only can provide service in the behavior for teachers and students, but also provide professional guidance. For example, the Yale University library, according to the specific professional and subject to set the appropriate expert librarians and provide professional services.

Cultivate the warm service, let the reader be able to relax when they enter into the library and improve the quality of learning.

\section{Conclusion}

In summary, under the current background of information, enhancing the service quality of the library is imminent. With the rapid rise of the knowledge economy, the development of the library also exist competition and the contest, because it is not only a static locker but a dynamic development and dissemination of knowledge network [9]. It is necessary to provide personalized service in the development of the times, attract students interest in reading, really do not waste resources library, provide personalized information service and the implementation of the service brand, which has become the main trend of the development [10]. The library service is also broad and profound. It needs to follow the changes of the times to adjust and improve the quality of the whole study. Competition among university libraries has become a service quality contest. It has become very important to attract readers with their own charm. Thus promote the vigorous development of the library cause and contribute to the development of the knowledge, and maximize the value of the library. Let good resources transfer in the minds of readers.

\section{References}

[1] Lane F C, Anderson B, Ponce H F, et al. Factorial invariance as a measure of library service quality over time [J]. Library \& Information Science Research, 2012, 34(1): 22-30.

[2] Mok C, Sparks B, Kadampully J. Service quality management in hospitality, tourism, and leisure [M]. Routledge, 2013.

[3] Papadomichelaki X, Mentzas G. e-GovQual: A multiple-item scale for assessing e-government service quality [J]. Government information quarterly, 2012, 29(1): 98-109.

[4] Kiran K, Diljit S. Modeling web-based library service quality [J]. Library \& Information Science Research, 2012, 34(3): 184-196.

[5] Reed K, McFarland D, Croft R. Laying the Groundwork for a New Library Service: Scholar-Practitioner \& Graduate Student Attitudes Toward Altmetrics and the Curation of Online Profiles [J]. Evidence Based Library and Information Practice, 2016, 11(2): 87-96. 
[6] Hunting S A, Ryan R, Dowler B. Collaborative library service delivery: A guide to regional library management models in NSW [J]. 2015.

[7] Allen H G. Analysis and Design of Structural Sandwich Panels: The Commonwealth and International Library: Structures and Solid Body Mechanics Division [M]. Elsevier, 2013.

[8] Price N J. Fault and Joint Development in Brittle and Semi-Brittle Rock: The Commonwealth and International Library: Geology Division [M]. Elsevier, 2015.

[9] Char B, Geddes K O, Gonnet G H, et al. Maple V library reference manual[M]. Springer Science \& Business Media, 2013.

[10] Beiner R. Political Judgement (Routledge Library Editions: Political Science Volume 20) [M]. Routledge, 2013. 